\title{
Does Your Ad Have Too Many Pictures?
}

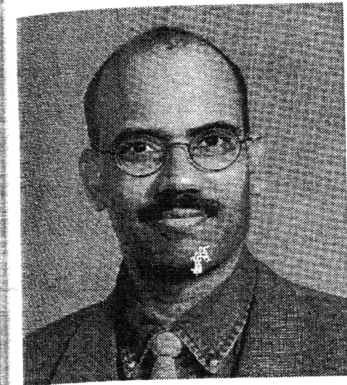

SURENDRA N. SINGH

University of Kansas

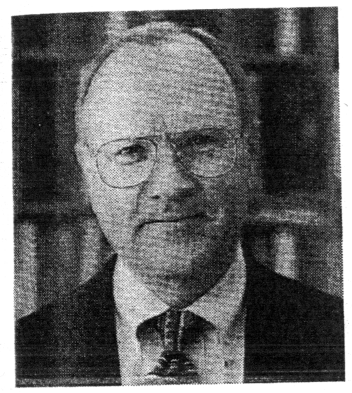

\section{PARKER LESSIG}

University of Kansas

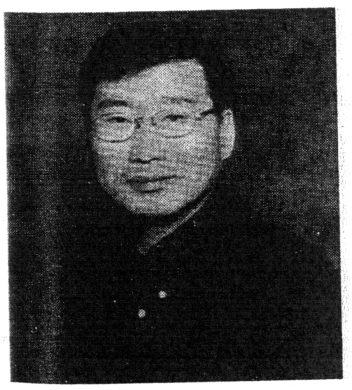

\section{DONGWOOK KIM}

Michigan Technological University

This paper reports findings from a study that evaluates the effectiveness of longer print advertisements - the advertisements with a low copy-picture ratio (i.e., primarily pictorial advertisements or PPAs). More specifically, the effectiveness of a long PPA with that of its shorter version is compared under varying conditions of processing effort, exposure, and clutter. Results from an initial study with student subjects as well as a partial replication with a community volunteer group indicate that the long PPA and its shorter version do not differ in either memory or attitudinal effectiveness. In addition, the results strongly suggest that using two exposures of a short PPA is a more effective media strategy than using one exposure of a long PPA. Finally, the theoretical, managerial, and public-policy implications of the findings as well as directions for future research are explored.

Pictorial ADVERTISEMENTs have always played a dominant role in print advertising (Edell and Staelin, 1983). These days, it is not uncommon to see six-page, eight-page, or even longer magazine advertisements with pictures that take up more than half the advertisement space. Advertisers use pictures for several reasons, including (1) to get attention, on the assumption that audiences examine the artwork of an advertisement first (Bolen, 1984); (2) to provide information about the brand; (3) to show how a product is used and who uses it; and (4) to create a brand image (Edell and Staelin, 1983; Unnava and Burnkrant, 1991a).

Notably, not all pictures in an advertisement contain product-relevant information. Many are peripheral pictures-pictures that do not provide unique information about the product/brand being advertised but are simply a part of the background. Regardless of their nature, pictures usually form the major component of a pictorial advertisement's visual syntext. The visual syntext is "represented by types of visual elements-products, people, situations, etc.-and their overall arrangement in terms of picture or illustration size,

The authors thank $H$. Rao Unnava for his valuable comments and for providing certain scales used in the study. Financial support by the University of Kansas General Research Fund is gratefully acknowledged. which can be regarded as analogous to sentence length" (Rossiter, 1981).

In this paper, our focus is on those longer print advertisements that have a low copy-to-picture ratio. We call such advertisements "primarily pictorial advertisements" (or PPAs). The broad question we ask is this: Do PPAs contain too many pictures? We specifically investigate the possibility of reducing the length of a long PPA by regrouping and/or excising peripheral pictures without compromising the effectiveness of the advertisement and thereby improving the efficiency of the advertising effort.

We address several research issues in this study, beginning with the fundamental question: Is a longer PPA more effective than its shorter version (created from the long PPA by consolidating and excising some peripheral pictorial elements while preserving the other portions of the advertisement)? From a strategic point of view, an advertiser has a choice: For roughly the same price, she or he can either use an n-page PPA or use two insertions of a $n / 2$-page version of the PPA. In a given magazine issue, is using two insertions of a short PPA more effective and efficient than using one insertion of the original PPA? This is the second issue we investigate in this study. Prima facie, it seems that a PPA having more pictures (and hence being longer) is more likely to cut through the media clutter than its shorter version. Exploring the role of clutter in determining the relative effectiveness of long and short versions of a PPA is 


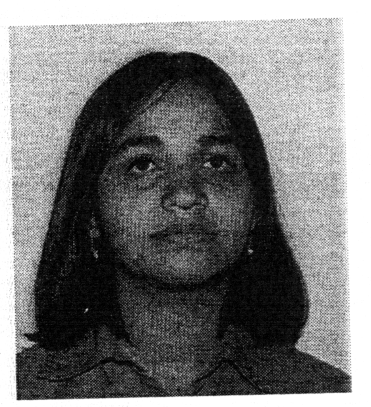

\section{REETIKA \\ GUPTA}

Baruch College, CUNY

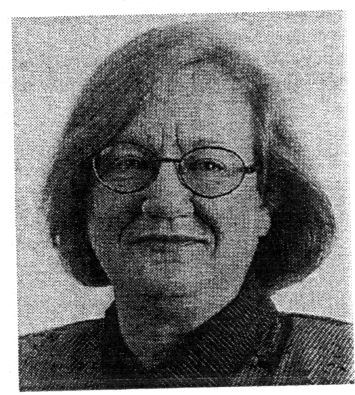

MARY ANN HOCUTT

Samford

University

the third research issue considered here. Lastly, it is expected that a highly motivated reader is less likely to be influenced by peripheral pictures in an advertisement. The moderating influence of reader motivation on the relative effectiveness of a longer versus a shorter PPA is the final research question addressed in our study.

Our study is important for theoretical as well as practical reasons. From a theoretical perspective, little research has examined the effects of nonverbal message elements on consumer information processing, and more research on that topic is needed (Houston, Childers, and Heckler, 1987). Previous studies have primarily compared the memory effectiveness of advertisements with pictures and words with that of words-only advertisements (see Houston, Childers, and Heckler, 1987; Leong, Ang, and Tham, 1996; and studies cited therein). We extended prior work by comparing the effectiveness of advertisements with few pictures with that of advertisements with more pictures in varied processing motivation, exposure, and clutter conditions. From a managerial standpoint, media expenditures are monumental and are surpassed only by the cost of distribution (Russell and Lane, 1993). If advertisers' objectives could be accomplished with advertisements containing fewer pictures, significant reductions in advertising-creation and media costs would result.

\section{LITERATURE REVIEW AND PREDICTIONS}

\section{Longer versus shorter PPAs:}

\section{Memory differences}

Are advertisements with more peripheral pictures more memorable than those with fewer pictures? Considerable evidence has accumulated showing that pictures are more memorable than words (see Leong, Ang, and Tham, 1996 and studies cited therein). The dominant explanation for that superiority is the ability of pictures to evoke mental images (Childers and Houston, 1984; Unnava and Burnkrant, 1991a). Relying on the dual coding model (Anderson and Reder, 1979), Unnava and Burnkrant (1991a) offer a succinct explanation of that effect:

According to the dual coding model, pictures are encoded as imaginal codes in memory and words are represented as verbal codes. However, pictures are also labeled more spontaneously than words are imaged (Paivio 1986, p. 160). Therefore, the formation of two codes, verbal and imaginal, is more likely for pictures than it is for words. The ease of formation of dual codes for pictures in comparison with words results in the "picture superiority effect" (the superior memorability of pictures over words) because the greater number of memory codes for pictures act as multiple retrieval routes to those pictures. A considerable body of research shows that the likelihood of retrieval is related directly to the number of alternative retrieval routes in memory (e.g., Anderson and Reder, 1979).

The imagery explanation of the picturesuperiority effect relates to advertisements where information presented in words is the same as the information presented in the pictures (Houston, Childers, and Heckler, 1987). The extent to which this explanation will apply to advertisements with more versus fewer peripheral pictures is not clear. However, for an advertisement with more peripheral pictures to have greater effectiveness, the additional peripheral pictures must produce higher mental imagery, which may in turn contribute to better encoding of the verbal arguments advanced in the advertising copy by creating multiple retrieval paths. The memory effectiveness of a long PPA in comparison with that of its shorter version should, therefore, depend on the imagery loss, if any, caused by the editing process. If the process of shortening an advertisement (by eliminating some pictures and regrouping/consolidating others) leads to a significant loss of imagery value, the long PPA might be more memorable than its shorter version. However, that effect should be moderated by the advertising-processing effort of the reader.

A reader's interest in processing an advertisement has a significant effect on advertising memory. An uninterested reader pays no attention to the advertisement or, at best, briefly processes only its executional characteristics (Burke and Srull, 1988). The resultant shallow sensory-level processing is more conducive to learning pictorial than verbal material (Childers and Houston, 1984). In contrast, a reader interested in buying the product in the near future may pay more attention to advertising and process the advertisement at 
a deeper, more semantic level by comparing and contrasting the features of competing brands (Biehal and Chakravarti, 1982), thus creating brand-attribute memory associations that generate multiple retrieval paths.

Hence, a long PPA's memory advantage, if any, over its shorter version should occur in low-effort processing conditions only. In high-effort conditions, the possible multiple retrieval path advantage of long PPAs is neutralized by the semantic processing that occurs in high-effort processing. If, despite the editing, the long and short versions do not differ in their imagery-inducing ability, no memory differences due to imagery would be expected. However, because the long PPA has more pictorial elements, higher recall of pictorial elements would be expected from the long PPA than from the short one. Additionally, in comparison with the high-effort processing condition, pictorialelement recall should be much higher in the low-effort condition where processing is likely to be shallow, peripheral, sensory, and therefore pictorial-element oriented.

\section{Memory effects over repeated exposures}

In terms of efficiency, a key question is whether one exposure of a long (n-page) PPA is better than two exposures of its shorter (say $n / 2$-page) version. As in both instances the advertiser is buying $n$ pages of media space in a given vehicle, the media cost would be the same; and as the shorter version is created by editing the longer one, no significant additional advertising creation costs would be incurred.

Many studies in verbal learning have demonstrated a positive relationship between exposure frequency and message memory (Crowder, 1976). Repetition enhances memory by strengthening memory traces because it increases redundancy and provides more opportunities to process the message (Pechmann and Stewart, 1988). The relationship between repeated exposure and message learning has been affirmed in numerous advertising studies (see Singh, Rothschild, and Churchill, 1988 and studies cited therein). The findings suggest that if, at a single exposure, the long and the short versions of a PPA are equal in their memory effectiveness (as would be expected if they were identical in their imagery value), repeating the short version should produce greater advertising memory than is produced by a single exposure of the long version.

The effects are less clear, however, when at one exposure the long version leads to better memory than the short one. In that case, the long advertisement's advantages due to its having more pictures, and hence higher imagery, are pitted against the added exposure advantage from repetition of the short version, and the relative memory effectiveness depends largely on the level of initial advantage of the long version at one exposure.

When two exposures of the short advertisement version result in higher memory than a single exposure of the long version, the effect should be moderated by the amount of clutter in the media vehicle. Because repeating a message reinforces the memory trace (by increasing the redundancy of information and by providing more opportunities to process the message), repetition is likely to counter the negative effects of clutter (e.g., interfering with a subject's ability to recall distinctive brand information, that is, subjects have difficulty associating specific attribute characteristics with specific brands). Hence, though two exposures should lead to better memory than one exposure, the beneficial effect of repetition should be stronger in high-clutter than in low-clutter conditions. Extending that line of reason- ing to the comparison between one exposure of a long PPA and two exposures of its shorter version, we would expect the beneficial effects, if any, of repeating the shorter version to be stronger in the highclutter than in the low-clutter condition.

Some may argue that a longer PPA has a noticeability advantage over its shorter version. Other things being equal, a long advertisement tends to be more noticeable than its shorter version, especially when the reader incidentally scans pages. The long advertisement has not only an advantage in relative size but also a greater probability of appearing where few competing elements are present. Indeed, numerous studies over the past 70 years have shown that long advertisements have greater noticeability and readership than shorter ones (see Hanssens and Weitz, 1980 and studies cited therein). The noticeability advantage comes at an increased cost, however. More importantly, noticeability does not increase monotonically with advertisement length; rather, diminishing returns set in quickly.

Consider Silk and Geiger's (1972) reanalysis of Copland's (1958) data investigating the relationship between advertisement size and advertising noting/reading. Their findings indicated that size advantage either flattens or declines significantly for advertisements beyond one-half page. Similar results were reported by Hanssens and Weitz (1980), who found that though advertising size was related strongly to "seen" and "read most" scores, the relationship showed diminishing returns. Given an average advertisement size of .79 page and a standard deviation of $.51,99$ percent of all advertisements used in the Hanssens and Weitz study had to be less than or equal to slightly more than two pages, assuming a normal distribution. Even at that length, diminishing returns were noticed. Thus, data from Silk 
and Geiger (1972) and Hanssens and Weitz (1980) suggest that the noticeability advantage begins to diminish as the advertisement size approaches one to two pages.

Based on the foregoing discussion, we summarize our predictions about the likely memory effects of a long PPA and its shorter version as follows:

1. A long PPA will lead to better advertising memory only if it exceeds its shorter version in imagery-evoking ability.

2. That effect is more likely in the loweffort than in the high-effort processing condition.

3a. The recall of pictorial elements will be higher for a long PPA than for its shorter version.

$3 b$. The recall of pictorial elements will be higher in low-effort processing conditions.

4a. If at one exposure a long and a short PPA are equal in their memory effectiveness, repeating the short version will promote greater memory of the advertisement's contents than using a single exposure of the longer one.

$4 b$. That effect will be greater in a highclutter than in a low-clutter condition.

5. In general, the effects of repetition will be moderated by clutter such that the beneficial effect of message repetition will be higher in the highclutter than in the low-clutter condition (i.e., an exposure by clutter interaction is expected).

\section{Likely attitudinal effects of primarily pictorial advertisements (PPAs)}

The evidence is mixed about the attitudinal effects of pictures in print advertisements. Some studies show a positive effect (e.g., Mitchell and Olson, 1981), while others show a negative effect (Kisielius and Sternthal, 1984). Moreover, two classes of explanations for those effects are offered: (1) the affect-transfer hypothesis that advertisements evoke affective responses, which in turn become associated with the advertised brand (Miniard et al., 1991; Mitchell, 1986) and (2) the belief structure change hypothesis that pictures' effect on attitudes occurs through their influence on product-related thoughts and beliefs (Mitchell and Olson, 1981). Once again, the above studies compare advertisements with pictures and words to wordsonly advertisements. To understand better how an advertisement with more pictures differs in attitudinal effects from an advertisement with fewer pictures, we offer an imagery-based explanation.

According to Paivio (1986), imagery is more likely to be evoked by and used with pictures than with words and "affective reactions would ordinarily occur more quickly to pictures than to words because the former have a more direct access to affect-mediating imagens" (Paivio, 1986). Therefore, other things being equal, it may be expected that more pictures should generate higher imagery and greater affective reactions. However, the affective reactions to pictures is likely moderated by the nature of both the processing and the picture itself (Miniard et al., 1991). Using the elaboration likelihood model (Petty and Cacioppo, 1981), Miniard and his coworkers found support for the hypothesis that when a picture conveys product-relevant information, its persuasive influence should grow as involvement increases. The reverse should occur for pictures that serve as peripheral cues; that is, their persuasive influence should grow in low-involvement conditions and decline in high-involvement conditions. The researchers stated:

In the case of affect-laden pictures that are peripheral to a product's merits, picture-based persuasion should be- come less potent as involvement increases and cease when involvement reaches a sufficiently high level. Conversely, the influence of pictures that serve as arguments should decline as involvement increases.... This moderation is expected even if a peripheral cue's influence operated through an affect-transfer process, because issuerelevant thinking is viewed as the dominant determinant of attitudes within the central route to persuasion.

Because the primary intent of our study was to understand the effect of removing certain peripheral pictures from long PPAs, Miniard et al. provide a means for making the following specific prediction:

Long PPAs, having a larger number of peripheral pictures than their shorter versions, engender greater positive attitudinal responses toward the ad in low-effort processing conditions only. Because the importance of peripheral pictures diminishes with increasing involvement, the long and short versions of a PPA should not differ in their attitudinal effectiveness in high-effort processing conditions.

\section{METHOD}

We tested our predictions in a study with student subjects. The length effect was then replicated in a second study that involved the regular population.

\section{Design}

The research had a 2 (versions of a primarily pictorial advertisement: long PPA versus short PPA) $\times 2$ (response set or advertising-processing effort: high-effort processing versus low-effort processing) $\times 2$ (levels of advertising exposure: one exposure versus two exposures) $\times 2$ (levels of clutter: high clutter versus low clutter) factorial design. 
TOO MANY PICTURES?

\section{Subjects}

Subjects were 404 undergraduate students at a large midwestern university. They were assigned randomly to treatment conditions. We eliminated nine subjects, distributed evenly across the cells, who had claimed to have seen the stimulus advertisement.

\section{Stimuli}

Criteria for selection of the long PPA for the study were that the advertisement (1) be primarily pictorial (i.e., have a copypicture ratio of no more than 50 percent), (2) have some peripheral pictures (pictures not conveying product-relevant information), (3) represent a product category relevant to student subjects, and (4) be at least four pages long. Evaluating a PPA's effectiveness in a forced-exposure setting poses a fundamental question: Given the forced exposure, how does one know that the comparisons between the long and short PPAs are really valid? That is, what if, in the natural reading conditions, the long PPA is more noticeable than the short one? Clearly, if a sizable percentage of readers of a magazine fail to notice the short version because of its length, the longer PPA is more effective. To avoid that possibility, we set a stringent four-page advertising-length criterion, which is two to four times the length at which diminishing returns are demonstrated empirically by Hanssens and Weitz (1980) and Silk and Geiger (1972), respectively.

An eight-page, black-and-white advertisement for an imported automobile was selected from a national magazine. We pretested the stimulus advertisement to ensure unfamiliarity. Of the 10 subjects who were shown the advertisement, only two thought they might have seen it but were not certain. The advertisement was then altered professionally so that the original brand name and the emblem were replaced with fictitious ones to avoid any contamination due to differences in prior advertising exposure or brand usage. As a precaution, the modified advertisement was pretested with 10 additional subjects, all of whom claimed never to have seen it.

The long (eight-page) version of the advertisement was then edited to create a shorter (four-page) PPA. In editing the advertisement, we attempted to (1) delete pictures that appeared to be peripheral and (2) consolidate various verbal/pictorial elements (i.e., rearrange the visual syntax) to conserve space. The information on the first two pages (53 words) and the prominent picture of the brand's model number and brand name from the last page of the advertisement were combined to create the first page of the short version. Four $31 / 2^{\prime \prime} \times 31 / 4^{\prime \prime}$ pictures (two from each of pages 3 and 6) were placed on one page, which became the second page, of the short advertisement version. The third and fourth pages of the short version were the unchanged fifth and seventh pages of the long version. Thus, the editing involved eliminating one peripheral picture (page 6), removing the largely pictorial first page (after moving the two lines of copy to another page), consolidating verbal information from pages 1, 2, and 8 plus the picture of the brand name from page 8 into one page, and placing pictures from pages 3 and 6 onto another page.

Sixteen advertising portfolios, each containing 12 advertisements (fillers and target advertisements), were prepared to operationalize the $2 \times 2 \times 2 \times 2$ design. The first page of each portfolio provided general instructions, including manipulation for processing effort (or response set). The second page contained instructions about the rating scales used in the study.

The fillers were low-familiarity magazine advertisements ranging in length from one to eight pages and representing product categories relevant to the subjects (e.g., clothing, wristwatches, bottled water) that were chosen from magazines of English-speaking foreign countries. The longer fillers were included to ensure that the stimulus advertisements, especially the long PPA, did not stand out and draw undue attention. Because the design had a repeated-exposure condition for the stimulus advertisements, we presented two filler advertisements twice to avoid the possibility of stimulus advertisements being singled out.

In the one-exposure condition, the stimulus advertisements (the long or short PPA, depending on the experimental condition) always appeared in the eighth position. In the two-exposure condition, the stimulus advertisements appeared in the fourth and eighth positions. In other words, we replaced the fourth filler advertisement with a stimulus advertisement to create the two-exposure condition.

The clutter condition was operationalized by replacing filler advertisements 2 and 10 from the low-clutter condition with two 2-page automobile advertisements for different imported automobiles. Prior studies (e.g., Burke and Srull, 1988) have demonstrated that when two competing brands share a common product class, the memory for one brand will interfere with the memory for the other brand. By having one automobile advertisement precede the stimulus advertisement and a second automobile advertisement follow it, we attempted to create both proactive and retroactive interference and thus a cluttered condition. To avoid any confusion about whether a piece of information came from the stimulus advertisement or the two distractor advertisements, all overlapping information between the stimulus and distractor advertisements was eliminated from the distractor advertisements.

The positions of all filler advertisements 
remained constant across all experimental conditions. The filler advertisements were arranged so that the first exposure of the stimulus advertisement was always preceded by the same filler advertisement. Also, the filler advertisement following the stimulus advertisement was the same in all conditions and was different from the one preceding the stimulus advertisement.

\section{Procedure}

Subjects participated in groups of two to ten. Upon arrival, they received an advertising portfolio and a ratings booklet with instructions for either the high- or loweffort advertising-processing condition based on those of Mitchell and Olson (1981), Burke and Srull (1988), and Unnava and Burnkrant (1991b). In the higheffort processing condition where the aim was to simulate effortful, semantic processing of the advertisements, instructions were designed to focus attention on the informativeness and meaning of the advertisements. In contrast, in the low-effort condition, subjects were instructed to focus on the executional (i.e., sensory) characteristics of the advertisement.

On the basis of prior studies (e.g., Fisk and Schneider, 1983; Unnava and Burnkrant, 1991b), we expected that orienting subjects' attention to different aspects of the advertisement (sensory characteristics versus meaning of the advertisement) should lead to differences in processing effort. Therefore, subjects in the higheffort condition were asked to read the advertisements carefully, understand their meanings, and rate their overall content on four seven-point semantic differential scales: easy to understand/difficult to understand, meaningful/not at all meaningful, informative/not at all informative, and strong/weak. Subjects in the loweffort condition were told to evaluate the advertisements' layout and overall appearance on two 2-item, 7-point semantic differential scales with anchors good/bad and attractive/unattractive. All six scales were taken from Unnava and Burnkrant (1991b).

Following Unnava and Sirdeshmukh (1994), we informed the subjects that the repetition of some advertisements was intentional so that we could study the effects of advertising repetition; we also told them that the repeated advertisements should not be ignored. In addition, for each advertisement, subjects were asked to indicate whether they had seen the advertisement before and, if so, when and where. After the subjects finished rating all advertisements, a questionnaire containing measurement scales was administered.

\section{Measures}

In addition to administering measures for manipulation checks, we also measured visual imagery, uncued and cued brand recall, claim recall, attitude toward the adaffective, attitude toward the ad-evaluative, attitude toward the brand, and purchase intentions. (For details, see the Appendix.)

\section{RESULTS}

\section{Manipulation checks}

Subjects in the high-effort condition reported expending significantly greater processing effort (mean $=5.36$ ) than those in the low-effort condition (mean $=3.04$, $t=17.40, p<.0001$ ). Also, as expected, subjects in the high-effort condition reported focusing more attention on content (high-effort group mean $=3.20$; low-effort group mean $=2.42, t=7.84, p<.0001$ ), and significantly less attention on the appearance and layout of the advertisements (high-effort group mean $=3.51$; low-effort group mean $=3.80, t=3.02, p<.003$ ) than those in the low-effort condition. Those results suggest that the processing effort manipulation worked.

\section{Visual imagery}

The long and the short PPAs did not differ on the one-item imagery scale (long PPA. mean $=4.65$, short PPA mean $=4.55, t=$ $.62, p<.54)$. Nor did the two PPAs differ on the four-item scale measuring the extent of visual imagery experienced by the subjects (long PPA mean $=17.08$, short PPA mean $=16.94, t=.24, p<.81$ ).

\section{Memory and attitudinal effects}

We tested various hypotheses by performing separate ANOVAs for each dependent variable and by conducting a series of $a$ priori and a posteriori comparisons among various cell means. (Complete ANOVA tables are available from the authors. All $a$ priori and a posteriori comparisons were made by t-ratio and Tukey's directional tests', respectively [Kirk, 1968].) Means and standard deviations are reported in Table 1.

Memory effects-uncued brand recall. Because the stimulus brand name consisted of two parts, brand recall was scored as 0 if no recall, $1 / 2$ if either half of the brand name was recalled, and 1 if both parts were recalled. We found no significant differences in uncued brand name recall between the long and the short PPAs $\left(F_{1,379}=.75, p<.39\right)$ or between the highand low-clutter conditions $\left(\mathrm{F}_{1,379}=.30, p<\right.$ .59). However, brand name recall was significantly higher in the high-effort processing condition (mean $=.46$ ) than in the low-effort condition (mean $=.30, \mathrm{~F}_{1,379}=$ $16.66, p<.001)$ and in the two-exposure condition (mean $=.43$ ) than in the oneexposure condition $\left(\right.$ mean $=.33, \mathrm{~F}_{1,379}=$ 7.67, $p<.006)$.

Cued brand recall. Neither the length of the PPA nor the level of exposure had any effect on cued brand recall $\left(\mathrm{F}_{1,379}=1.73\right.$, $p<.19$, and $F_{1,379}=1.42, p<.24$, respectively). Cued brand recall was higher in 


\section{TABLE 1}

Means for Brand Name Recall (Uncued and Cued), Claim Recall, Pictorial Elements Recall, Attitude toward the Ad (Affective and Evaluative) Attitude toward the Brand, and Purchase Intentions (Standard Deviation in Parentheses)

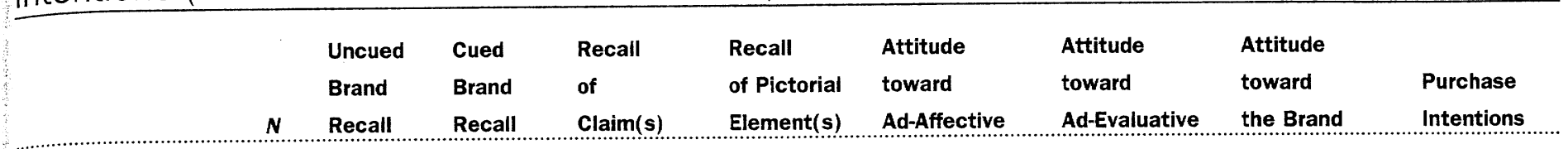

Short PPA

Low Effort

Low Clutter

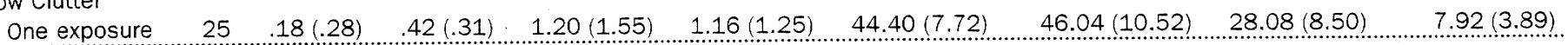

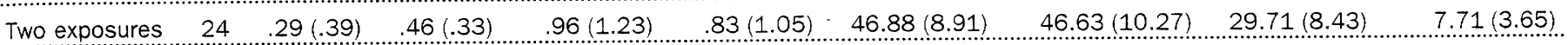

High Clutter

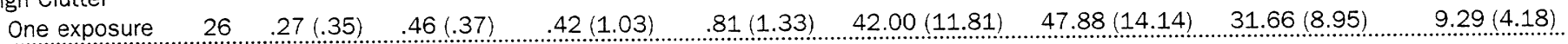

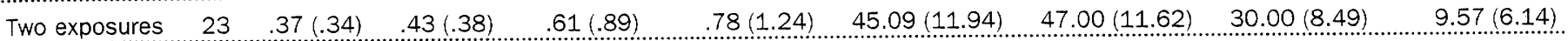

High Effort

Low Clutter

One exposure $\quad 25 \quad .48(.39) \quad .66(.35) \quad 3.96(3.90) \quad .68(.95) \quad 40.80(11.50) \quad 57.12(9.54) \quad 38.76(7.11) \ldots 13.32(4.54)$

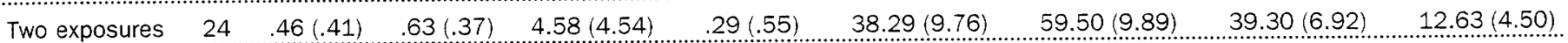

High Clutter

One exposure $25 \quad .34(.40) \quad .44(.39) \quad 1.48(1.48) \quad .92(1.47) \quad 38.48(9.84) \quad 54.16(9.86) \quad 37.08(6.74) \quad 13.08(5.41)$

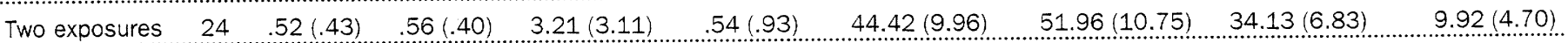

\section{Long PPA}

Low Effort

Low Clutter

One exposure $22 \quad .25(.40) \quad .55(.41) \quad 1.14(1.78) \quad 1.32(1.39) \quad 45.82(11.62) \quad 46.86(13.28) \quad 30.86(9.34) \ldots . .73(5.30)$

\begin{tabular}{|c|c|c|}
\hline Two exposures & 25 & \\
\hline
\end{tabular}

High Clutter

One exposure $\quad 25 \quad .34(.43) \quad 48(42) \quad .56(.96) \quad .72(1.10) \quad 45.39(11.96) \quad 48.36(14.29) \quad 29.17(11.17) \quad 8.64(5.60)$

$\begin{array}{llllllllll}\text { Two exposures } & 25 & .32(.38) & .54(.43) & .88(1.62) & .80(1.26) & 46.56(9.98) & 45.76(12.28) & 30.20(7.71) & 8.72(5.33)\end{array}$

High Effort

Low Clutter

One exposure $26 \quad .48(.33) \quad .65(.31) \quad 4.27(3.12) \quad .62(1.13) \quad 38.08(8.62) \quad 54.68(10.59) \quad 36.65(5.92) \quad 12.50(5.74)$.

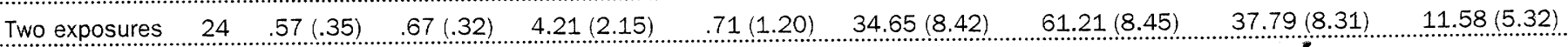

High Clutter

One exposure $\quad 25 \quad .28(.36) \quad .42(.43) \quad 1.24(1.23) \quad .68(1.14) \quad 39.83(11.19) \quad 55.16(12.63) \quad 36.64(8.26) \quad 12.20(4.88)$

$\begin{array}{llllllllll}\text { Two exposures } & 27 & .52(.38) & .59(.39) & 3.74(2.74) & .85(1.49) & 37.85(10.18) & 58.33(10.18) & 38.89(5.14) & 11.78(4.77)\end{array}$

the high-effort processing condition (mean $=.58)$ than in the low-effort condition (mean $=.49, \mathrm{~F}_{1,379}=5.7, p<.017$ ). Also, subjects in the low-clutter condition had a significantly higher cued brand recall (mean $=.57$ ) than those in the highclutter condition $\left(\right.$ mean $=.49, \mathrm{~F}_{1,379}=4.76$, $p<.03)$.

Recall of claims. Informational elemerits from the long and the short stimulus PPAs were recorded. Two judges unfamiliar with the study coded 50 (of 395) questionnaires for claim recall. The claim recall score of each subject was the total number of matches found between the informational elements in the subject's protocol and those of the long or the short PPA, depending on whether the subject was assigned to the long or the short PPA condition. (Note that the long and short PPAs had the same informational elements, but the short advertisement had two fewer pictures than the long one.) The judges agreed on 96 percent of responses. Their differences on the remaining 4 percent were resolved by mutual discussion. Given the high degree of agreement, the rest of the data were coded by one judge.

The long and short PPAs did not differ on claim recall $\left(\mathrm{F}_{1,379}=.22, p<.64\right)$. Processing effort, clutter, and level of exposure all had significant main effects on 
claim recall as well as on the following two-way interactions: processing effort $x$ clutter $\left(F_{1,379}=7.77, p<.006\right)$, processing effort $\times$ level of exposure $\left(F_{1,379}=5.42\right.$, $p<.02$ ), and clutter $\times$ level of exposure $\left(\mathrm{F}_{1,379}=5.14, p<.024\right)$. Those interactions are plotted in Figures 1 through 3 , respectively.

Figure 1 demonstrates the detrimental effect of clutter on memory of claims. Subjects in the high-effort processing condition recalled significantly more claims (mean $=3.34$ ) than those in the low-effort condition (mean $=.88$ ), but that effect was accentuated in the low-clutter condition.

Figure 2 shows how the main effect of processing effort becomes more pronounced in the two-exposure condition. At one exposure, subjects in the higheffort condition recalled nearly 3.5 times more claims than those in the low-effort condition. However, the ratio reached to 4.22 at the two-exposure level.

Figure 3 depicts the beneficial effects of repeat exposure in the high-clutter condition. Whereas claim recall in the lowclutter condition is nearly identical in the one-exposure and two-exposure conditions, subjects recalled 2.35 times as many claims at the two-exposure level as they did at the one-exposure level in the highclutter condition; however, the difference is not significant at the conventional alpha level of $.05(p<.10)$.

Pictorial element recall. An ANOVA was performed on the number of pictorial elements recalled. A significant main effect for processing effort on pictorial element recall was found with subjects recalling

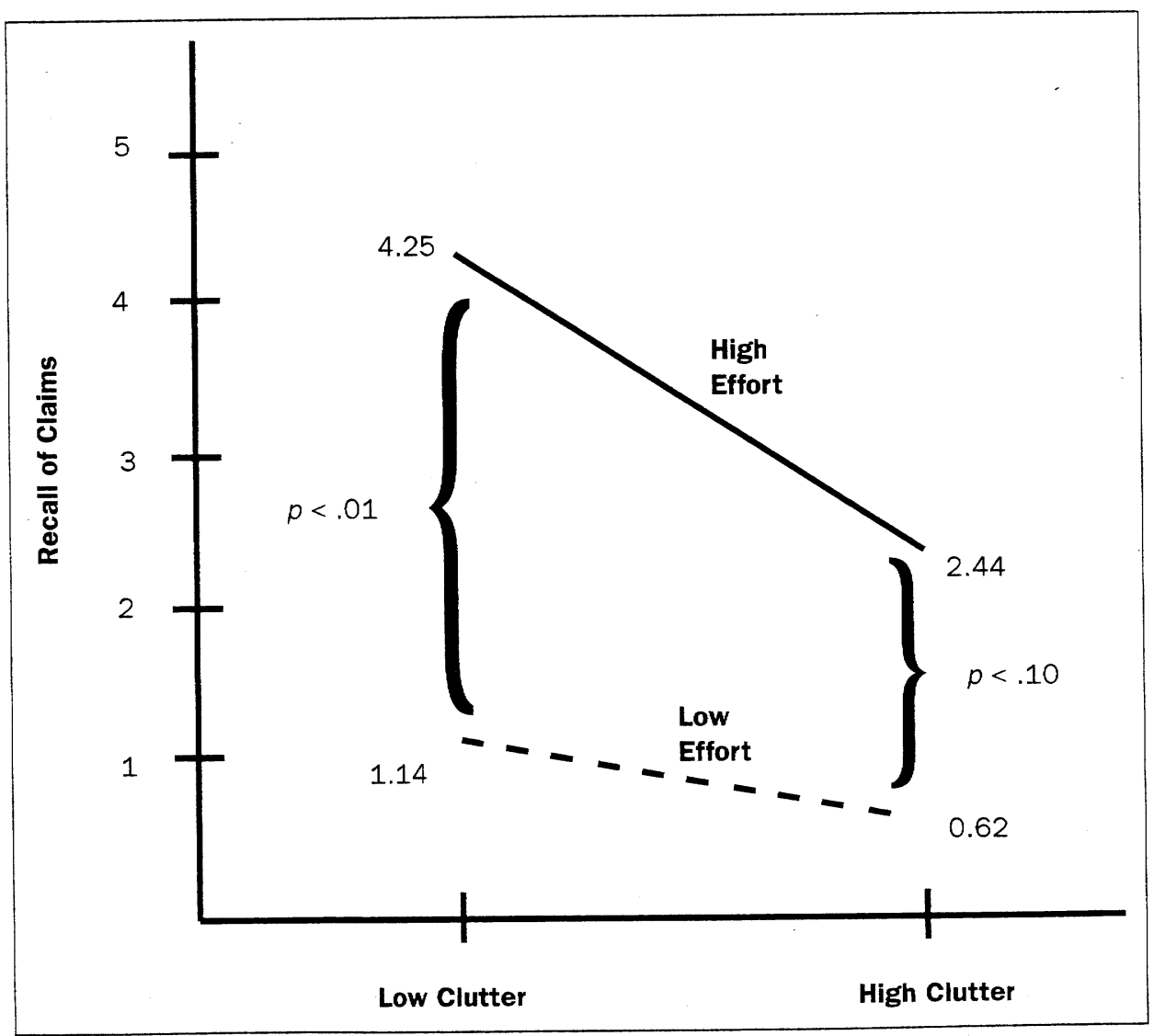

Figure 1 Recall of Claims: Clutter by Processing Effort Interaction nearly 1.5 times more pictorial information in the low-effort condition (mean = .99) than in high-effort condition (mean = .66, $\left.\mathrm{F}_{1,379}=7.27, p<.007\right)$. However, a significant interaction between advertising processing effort and clutter $\left(\mathrm{F}_{1,379}=\right.$ $6.05, p<.014)$, plotted in Figure 4 , shows that the effect occurred in the low-clutter condition only.

As predicted, subjects had a higher visual element recall (mean $=.89$ ) in the long than in the short PPA condition (mean $\left.=.76, \mathrm{~F}_{1,379}=1.48, p<.23\right)$, but the difference is not statistically significant.

Attitude toward the ad-affective $\left(\mathrm{A}_{\mathrm{ad}^{-}}\right.$ affective). A significant main effect for processing effort $\left(F_{1,379}=35.46, p<.001\right)$ and a significant interaction between processing effort and length $\left(F_{1,379}=4.22, p<\right.$ .041) were obtained. The interaction plotted in Figure 5 suggests that $A_{a d}$-affective is generally higher in the low-effort (mean $=45.3$ ) than in the high-effort (mean = 39.1) processing condition, but the effect is stronger for the long PPA than for the short one. However, that finding does not suggest the long PPA (mean: $\mathrm{A}_{\mathrm{ad}}$-affective $=46.03$ ) generated significantly higher affective attitudinal responses than the short one (mean: $\mathrm{A}_{\mathrm{ad}}$-affective $=44.55$, Tukey's $q=1.41, p>.10)$ in the low-effort processing condition.

Attitude toward the ad-evaluative ( $\mathrm{A}_{\mathrm{ad}^{-}}$ evaluative). The only statistically significant effect for $\mathrm{A}_{\mathrm{ad}}$-evaluative is the main effect of processing effort. Subjects in the high-effort condition had significantly higher $\mathrm{A}_{\mathrm{ad}}$-evaluative scores (mean = 56.51) than subjects in the low-effort condition (mean $=47.37, \mathrm{~F}_{1,379}=62.07, p<$ $.001)$.

Attitude toward the brand $\left(A_{B}\right)$. Subjects in the high-effort condition had a significantly higher $A_{B}$ score (mean = 37.41) than 


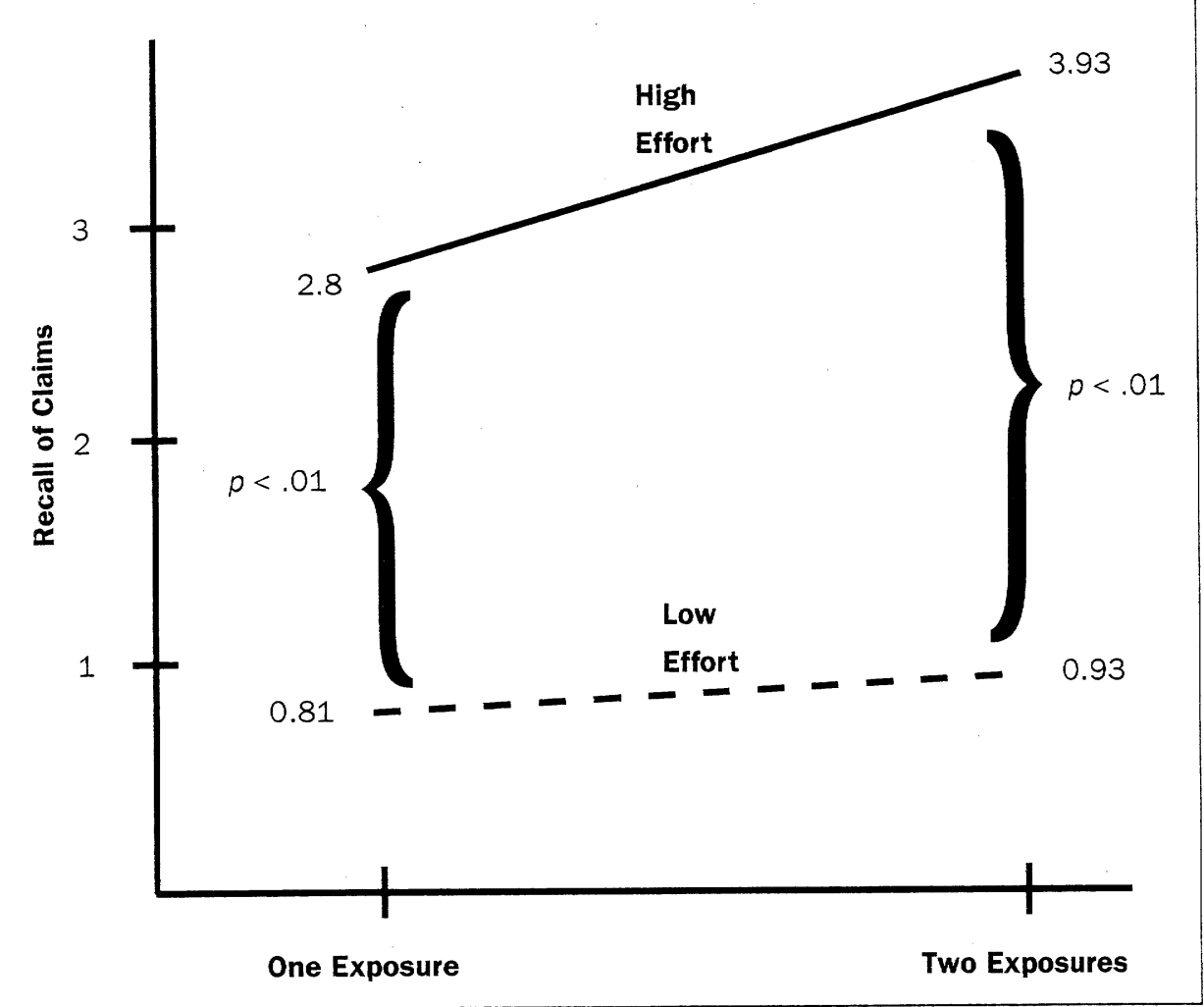

Figure 2 Recall of Claims: Exposure by Processing Effort Interaction

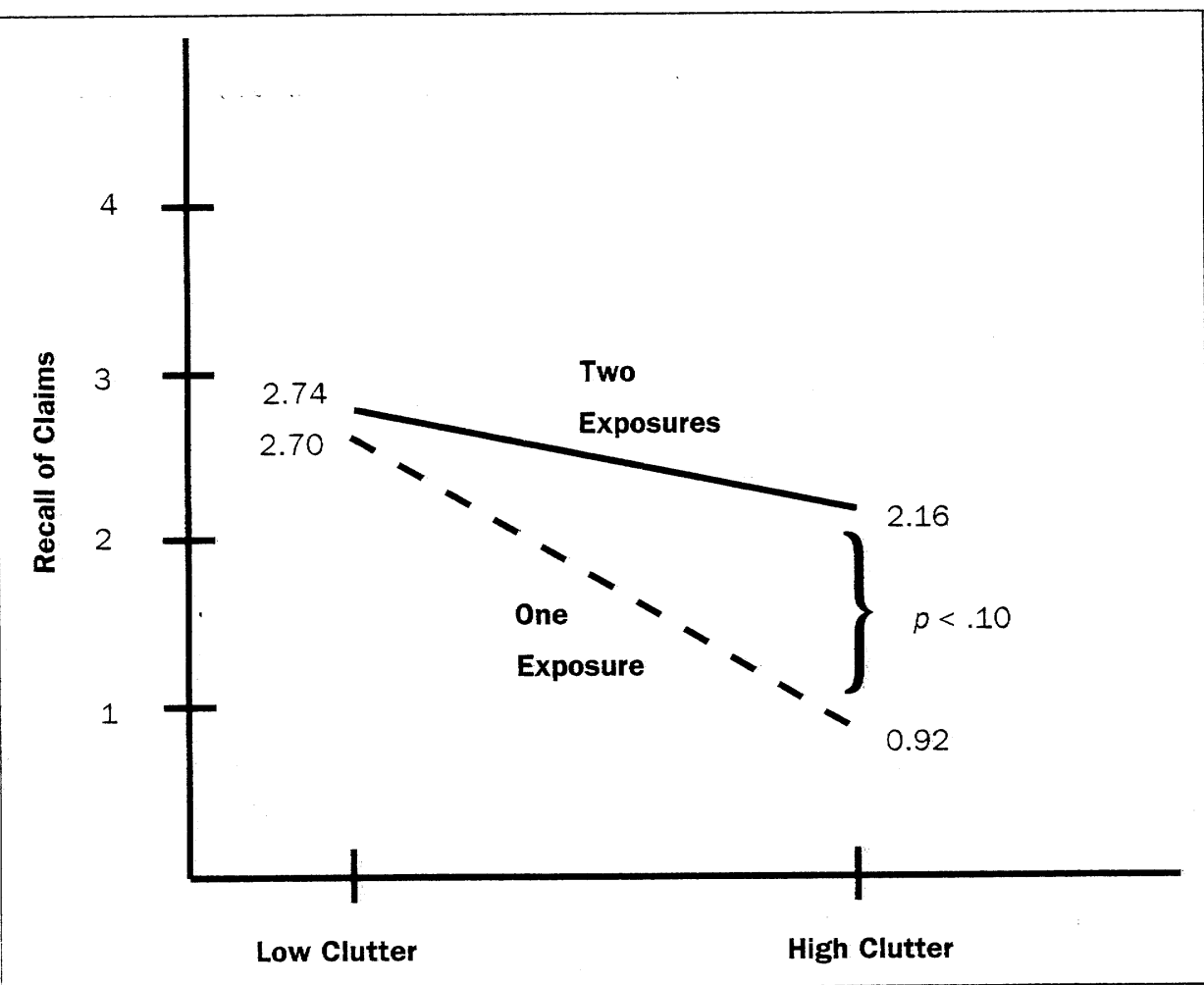

Figure 3 Recall of Claims: Clutter by Exposure Interaction their low-effort counterparts (mean = $30.40, \mathrm{~F}_{1,379}=76.23, p<.001$ ). However, $\mathrm{a}$ significant three-way interaction (see Figure 6) among effort, length, and clutter $\left(\mathrm{F}_{1,379}=5.77, p<.017\right)$ is present. It suggests that in the high-effort condition, the short advertisement had a significantly higher $\mathrm{A}_{\mathrm{B}}$ score in the low-clutter (mean = 39.02) than in the high-clutter (mean = 35.63, Tukey's $q=3.02, p<.05$ ) condition. No other cell mean comparisons are statistically significant.

Purchase intentions (PI). Processing effort is the only independent variable that significantly affected PI. Subjects in the high-effort condition had higher intention to purchase the advertised brand (mean = 12.13) than those in the low-effort condition (mean 3.81; $F_{1,379}=43.59, p<.001$ ).

One exposure of the long PPA versus two exposures of the short PPA. Because no significant length by exposure interactions are present, the long and short PPAs appear to be equal in their memory effectiveness at one exposure. We therefore compare the mernory effects of the long PPA at one exposure with those of the short PPA at two exposures.

In general, two exposures of the short PPA were more effective in promoting brand name recall (21 percent higher uncued brand recall, $p<.10$ ) and claim memory (28 percent higher claim recall, $p<.10$ ). However, as expected, in cluttered media conditions, the effects of two exposures of the short PPA were much stronger, resulting in 32.3 percent higher uncued brand recall $(p<.05)$ and 116 percent higher claim recall $(p<.025)$.

\section{A limited replication}

In order to ensure that results were not idiosyncratic to student subjects, a limited replication of the study was performed with subjects drawn from the population at large. In the replication, we dropped 


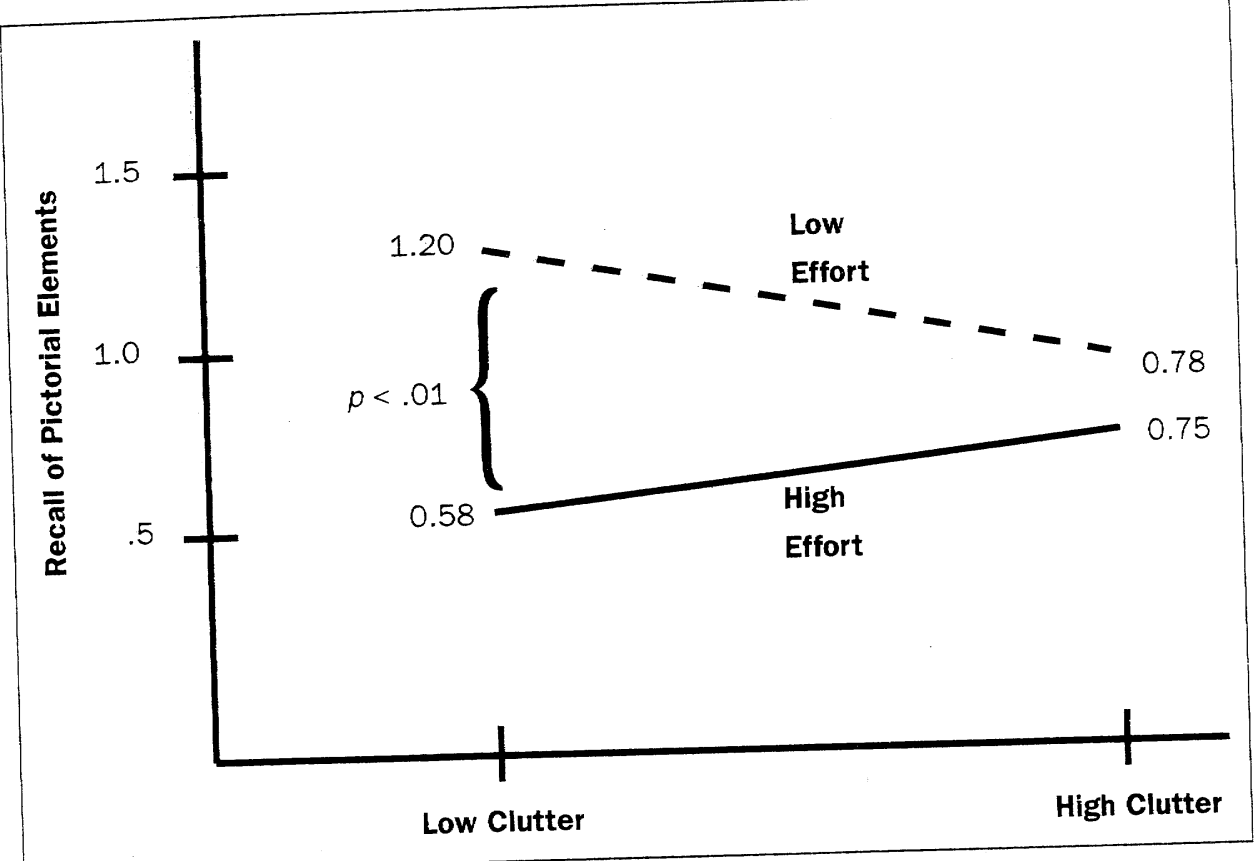

Figure 4 Recall of Pictorial Elements: Clutter by Processing Effort Interaction

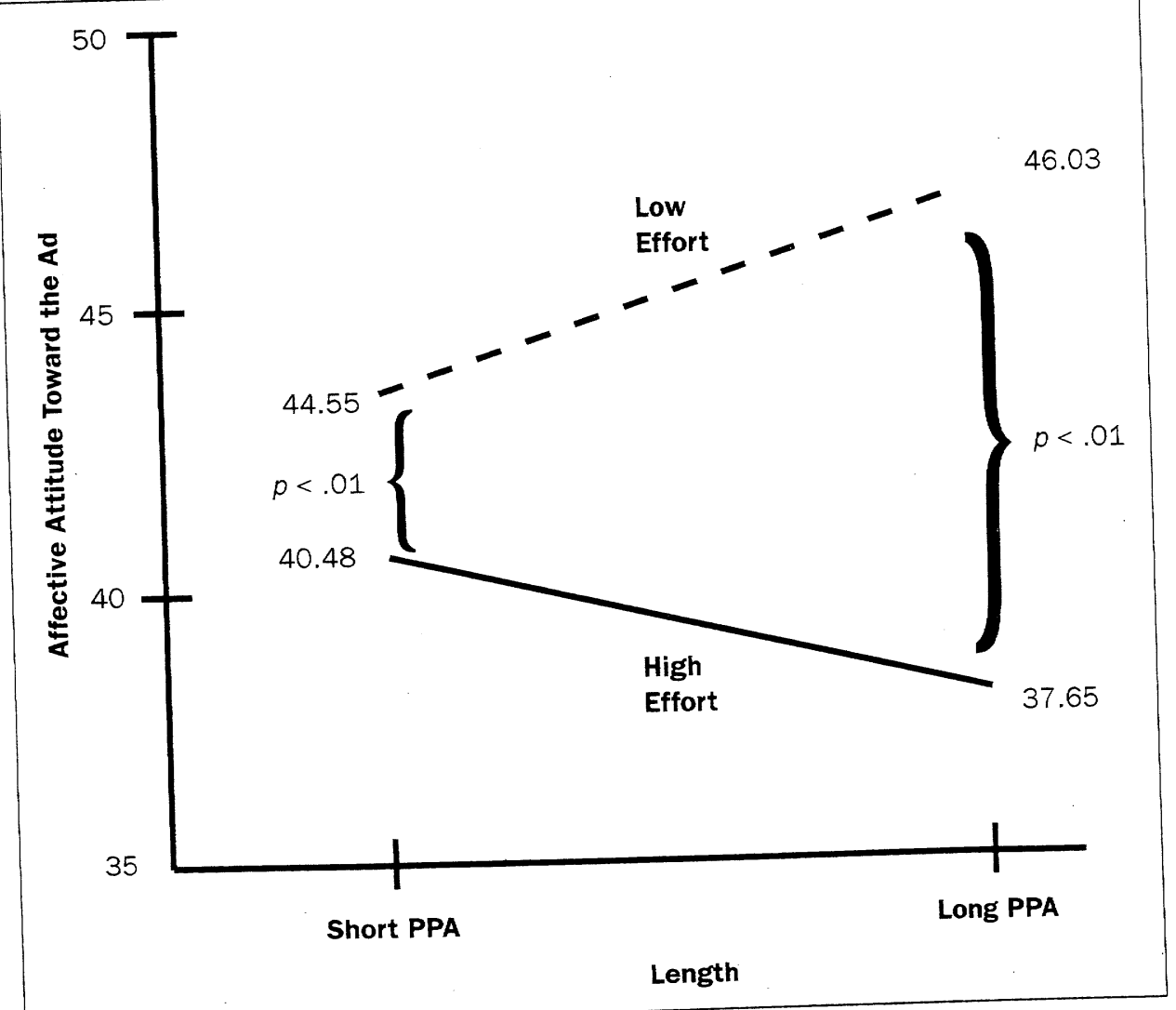

Figure 5 Affective Attitude toward the Ad: Length by Processing Effort Interaction the high-effort and high-clutter conditions based on the following rationale.

For theoretical reasons, we did not expect the length of the PPA to have a major effect on advertising-effectiveness in the high processing effort condition, and our findings with students substantiate that assumption. We obtained no advertisinglength by processing effort interactions for any of the recall variables. The only significant interactions between length and processing effort occurred for $A_{a d}$-affective and $A_{B}$ (see Figures 5 and 6, respectively). Figure 5 shows that, in general, $\mathrm{A}_{\mathrm{ad}}$-affective is higher in low-effort than in high-effort conditions. Also, in higheffort conditions, longer PPA induces much less favorable affective responses than the shorter PPA. Figure 6 shows a three-way interaction for $A_{B}$-between length, processing effort, and clutter. It is clear from Figure 6 that in high processing effort and low-clutter conditions, the shorter PPA is in fact better in positively influencing $A_{B}$ than the longer PPA, i.e., a longer PPA may be a liability in high processing effort conditions. Hence, dropping the high processing effort condition made sense.

We dropped the high-clutter condition also because it, too, had no appreciable interaction with advertisement-length. The only significant interaction between length and clutter is a three-way interaction between length, processing effort, and clutter, which is shown in Figure 5 and discussed above. Dropping the higheffort condition made this interaction moot and justified removing the highclutter condition.

Given only two levels of clutter and two levels of processing effort in the design, removal of high-clutter and high-effort conditions reduced the research design for the replication to a $2 \times 2$ design. The replication thus consisted of a $2 \times 2$ factorial design, which required presenting two 


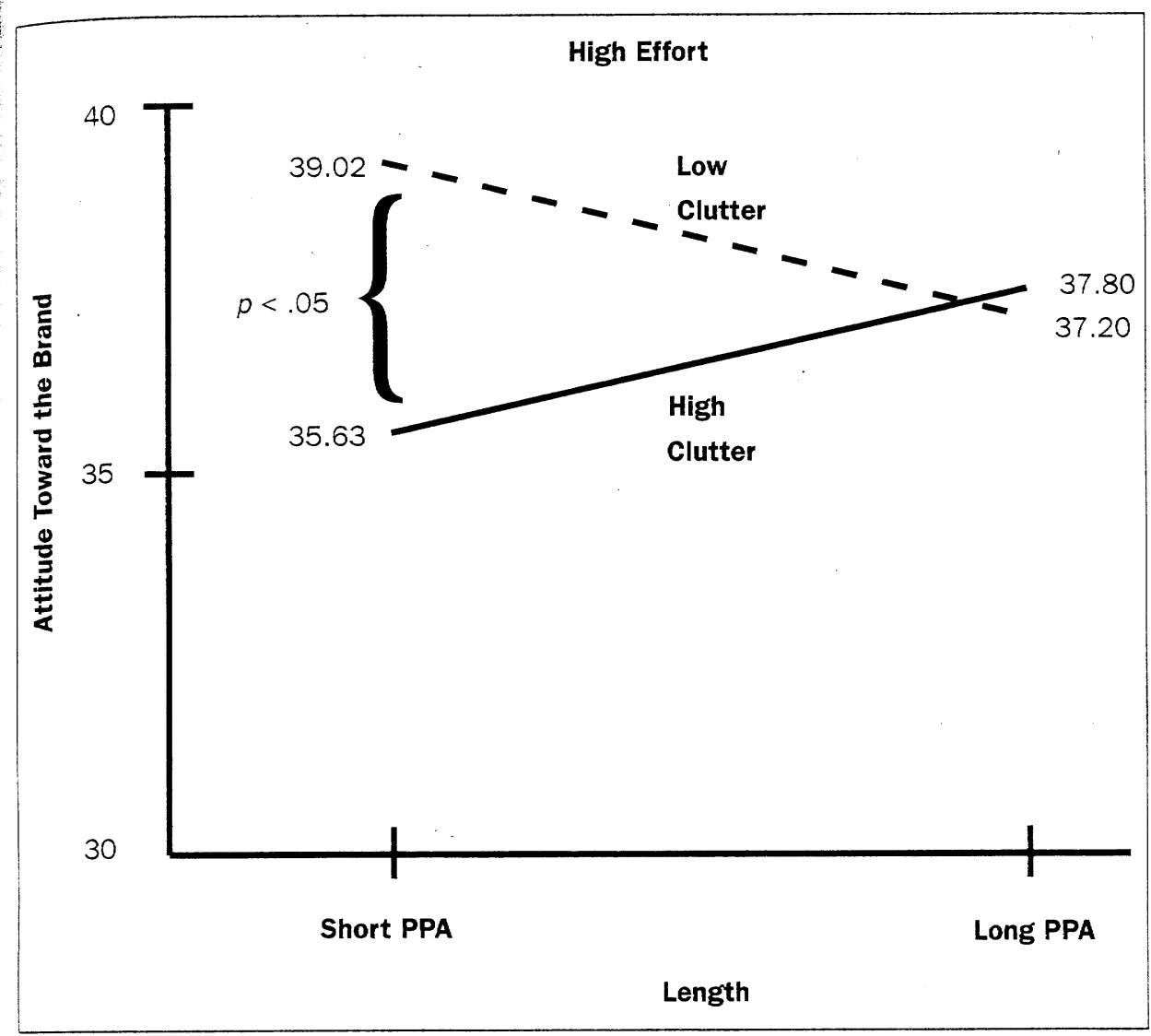

Figure 6 Attitude toward the Brand: Length by Processing Effort by Clutter Interaction

versions of a PPA (long versus short) at two repetition levels (one exposure versus two exposures).

Subjects were 35 males and 33 female volunteers, who were Boy Scout leaders in the local community. The sample was truly a microcosm of the community at large. It comprised a cross-section of people from different academic backgrounds, income groups, and socioeconomic groups. The average age of participants was 44 years. The Boy Scout organizations to which the leaders belonged received donations ( $\$ 5.00$ per subject). Cell sizes varied from 16 to 18 . The stimuli, procedure, and the measures were identical to the ones used in Experiment 1 with the exception that there were no portfolios representing the high-effort arid high-clutter conditions.
The results showed that the second exposure to the message did not have a significant effect on either memory or attitudes. Given low-effort, i.e., incidental learning situation, this result was not surprising. Like Study 1, the length of the message did not have a significant effect on any dependent variable except $\mathrm{A}_{\mathrm{ad}}$ evaluative. It turned out that the shorter advertisement (mean $=40.033$ ) was evalu-

\section{TABLE 2}

ated more favorably than the longer one $\left(\right.$ mean $\left.=32.54, \mathrm{~F}_{1,64}=5.23, p<.026\right) . \mathrm{A}$ similar result was obtained for $\mathrm{A}_{\mathrm{ad}^{-}}$ affective as well, but it did not approach the conventional significance level (short $\mathrm{PPA}$ mean $=42.9$, long $\mathrm{PPA}$ mean $=37.33$, $\left.F_{1,64}=3.22, p<.08\right)$. What these results seem to suggest is that an unduly long pictorial advertisement may be causing distraction, reactance, and negative feelings and evaluations.

A comparison of one exposure of the long PPA with two exposures of the short PPA, like Study 1, revealed striking effects on attitudinal measures, as shown in Table 2 (only statistically significant results are reported). Two exposures of the short PPA generated 33 percent higher $A_{\text {ad }}$-affective scores and 30 percent higher $A_{\text {ad }}$-evaluative scores than one exposure of the long PPA.

\section{DISCUSSION}

Table 3 provides a qualitative summary of our results. The results, from Experiment 1, clearly indicate that an eight-page PPA and its four-page version do not differ in either memory or attitudinal effectiveness. The most straightforward interpretation of those results is that because the two advertisements are equal in imagery value, no differences in performance should be expected. The "null" hypothesis of no difference in this case is acceptable, based on the fact that (1) the advertisement used was a "real-world" one and (2) several criteria for accepting a null hy-

Comparison of One Exposure of the Long PPA with Two Exposures of the Short PPA in Study 2

\begin{tabular}{|c|c|c|c|}
\hline & $\begin{array}{l}\text { One Exposure of } \\
\text { the Long PPA }\end{array}$ & $\begin{array}{l}\text { Two Exposures of } \\
\text { the Short PPA }\end{array}$ & p-value $<$ \\
\hline A $_{a d}$-affective & 33.47 & 44.39 & .01 \\
\hline$A_{a d}$-evaluative & 30.71 & 39.89 & .05 \\
\hline
\end{tabular}




\section{TABLE 3}

\section{A Summary of Results}

\section{Study with Student Subjects}

\begin{tabular}{|c|c|c|c|c|c|c|c|c|}
\hline Main Effects & $\begin{array}{l}\text { Uncued } \\
\text { Brand } \\
\text { Recall }\end{array}$ & $\begin{array}{l}\text { Cued } \\
\text { Brand } \\
\text { Recall }\end{array}$ & $\begin{array}{l}\text { Recall } \\
\text { of } \\
\text { Claim(s) }\end{array}$ & $\begin{array}{l}\text { Recall } \\
\text { of Pictorial } \\
\text { Element(s) }\end{array}$ & $\begin{array}{l}\text { Attitude } \\
\text { toward } \\
\text { Ad-Affective }\end{array}$ & $\begin{array}{l}\text { Attitude } \\
\text { toward } \\
\text { Ad-Evaluative }\end{array}$ & $\begin{array}{l}\text { Attitude } \\
\text { toward } \\
\text { the Brand }\end{array}$ & $\begin{array}{l}\text { Purchase } \\
\text { Intentions }\end{array}$ \\
\hline Length & 0 & 0 & 0 & 0 & $0 * *$ & 0 & ott & 0 \\
\hline Repetition & + & 0 & $+*$ & 0 & 0 & 0 & 0 & 0 \\
\hline Processing effort & + & + & $+*$ & $-\dagger$ & $\begin{array}{c}-* * \\
-* *\end{array}$ & + & $++\dagger$ & + \\
\hline Clutter & 0 & - & $-*$ & o† & 0 & 0 & $0+t$ & 0 \\
\hline $\begin{array}{c}\text { Two repetitions of short PPA vs. } \\
\text { One exposure of a long PPA }\end{array}$ & $++^{\odot}$ & 0 & $+\odot$ & 0 & 0 & 0 & 0 & 0 \\
\hline
\end{tabular}

One exposure of a long PPA

t: For "Pictorial Element Recall" there was a significant interaction between Processing effort $\times$ Clutter (see Figure 4).

**: For "Attitude toward Ad-Affective" there was a significant interaction between Processing effort $\times$ Length (see Figure 5).

tt: For "Attitude toward the Brand" there was a significant interaction between Processing effort $\times$ Length $\times$ Clutter (see Figure 6).

$\odot$ : Two repetitions of the short PPA were more effective in promoting brand name recall $(21 \%$ higher uncued brand recall, $\mathrm{p}<.10)$ and claim memory $(28 \%$ higher claim recall, $\mathrm{p}<.10)$. Limited Replication with Adult Subjects

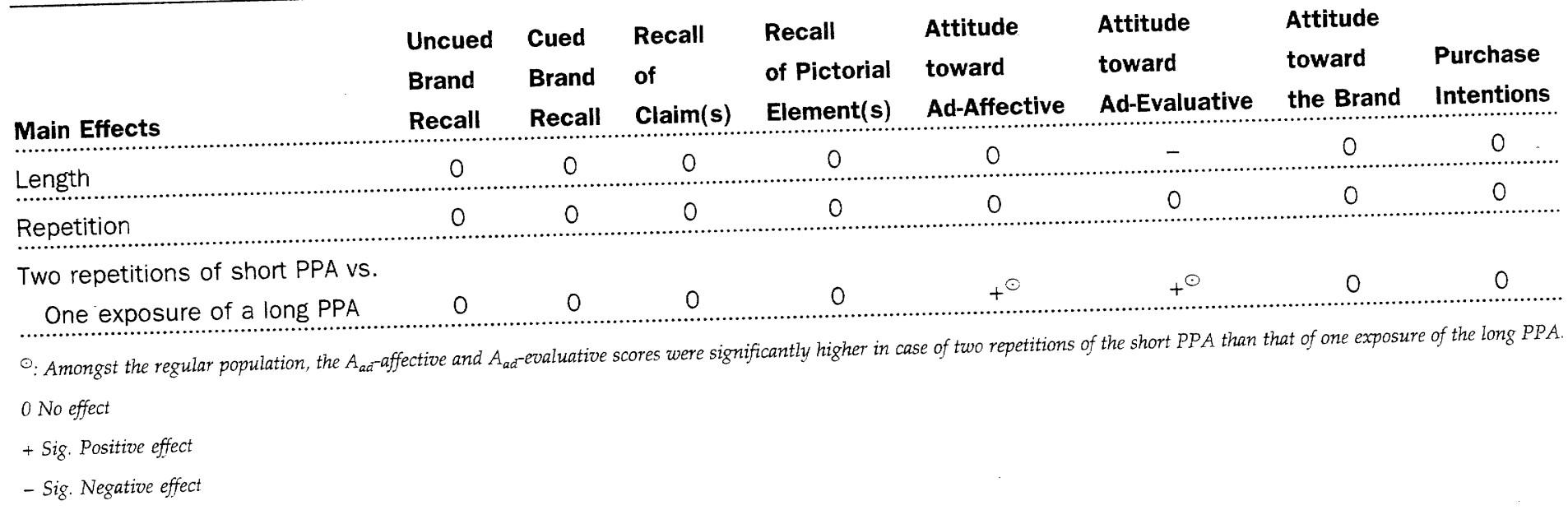

pothesis suggested by Frick (1995), such as a $p$-value greater than 0.5 (in our case, $p$ $<.81$, and .54 on the two imagery scales, respectively), large number of subjects ( $n$ =395), and sound measurement (the multi-item imagery scale borrowed from Unnava and Burnkrant, 1991a, had an $\alpha=$ .91) are met.

Why do the two PPAs not differ in their imagery value though? Two explanations are possible. First, perhaps the two pictures deleted from the long PPA were of such low imagery value that their removal had no effect on imagery. Second, the regrouping of pictures in creating the short PPA may have increased imagery through enhanced relational processing. (Relational processing occurs spontaneously and involves "focusing on similarities or shared themes among disparate pieces of information"-Meyers-Levy; 1991.) That effect could have compensated for the imagery loss due to removal of the two pictures.
Our predictions about the role of repetition in promoting memory for the message are generally verified. Not only did two exposures produce greater message memory than one exposure, but the effect was more pronounced in the cluttered condition. In the two-exposure cluttered condition, uncued brand name recall and number of claims recalled were 39 and 40 percent higher, respectively, than they were at the one-exposure level.

Even more revealing is the comparison 
between the long and the short PPAs at one and two exposures. In the main study, in the low-clutter condition, two exposures of the short PPA generated 21 percent higher uncued brand recall and 28 percent higher claim recall than one exposure of the long PPA. For the same comparisons in the high-clutter condition, the results are striking: 45 percent higher uncued brand recall and 116 percent higher
In contrast to the study with student subjects, the replication study showed a clear superiority of the shorter PPA over the longer one on $\mathrm{A}_{\mathrm{ad}}$-evaluative.

In the main study, an interesting aspect of the attitudinal results is the opposite directions of the affective and evaluative attitudes under the low- and high-effort processing conditions. $\mathrm{A}_{\mathrm{ad}}$-affective is significantly higher in the low-effort (mean =

\section{. . . under the conditions used in our two studies, a four- page version of a PPA is just as effective as its eight- \\ page parent.}

claim recall for two exposures of the short PPA. Similar results were obtained for the replication study with real-world subjects. Though not statistically significant, two exposures of the shorter PPA resulted in 26 percent higher claim recall than one exposure of the longer PPA. Moreover, as mentioned before, two exposures of the short PPA generated 33 percent higher $A_{\text {ad-affective score and } 30 \text { percent higher }}$ $\mathrm{A}_{\mathrm{ad}}$-evaluative score than one exposure of the long PPA. Those results strongly suggest that using two exposures of a shorter PPA is a more effective strategy than using one exposure of a long. PPA.

No main effects of length were observed in the main study for any attitudinal dependent measure. Our only prediction about attitudinal variables was an interaction between advertisement length and processing effort. Specifically, under the low-effort processing conditions, the long PPA was expected to produce more positive attitudinal responses than the short PPA. A length by processing effort interaction is found for $\mathrm{A}_{\mathrm{ad}}$-affective, but the two PPAs are not significantly different in attitudinal responses (see Figure 5).
45.3) than in the high-effort (mean = 39.1) processing condition. The opposite is true for $A_{a d}$-evaluative, which is significantly higher (mean $=56.51$ ) in the high-effort than in the low-effort (mean $=47.37$ ) processing condition. Given the evaluative nature of the $A_{B}$ and PI scales (see the Measures section), it is not surprising that the pattern of results for those measures is identical to that of $\mathrm{A}_{\mathrm{ad}}$-evaluative (i.e., both $A_{B}$ and PI are significantly higher in the high-effort than in the low-effort condition).

The preceding pattern demonstrates that the central and peripheral routes to persuasion (operating under the high- and low-effort processing conditions, respectively) have opposite effects on affective and evaluative dimensions of attitudinal responses. The results are consistent with (1) Greenwald and Leavitt's (1984) principle of higher-level dominance (PHLD), which suggests that cognitive evaluations dominate affective processing when involvement is high (cf. Batra, 1986), (2) Batra's (1986) assertion that manifestation of affective responses requires low-effort processing conditions, and (3) Madden,
Allen, and Twible's (1988) view that "careful cognitive consideration of an ad may actually inhibit its potential for evoking an affective reaction."

In summary, the single most important finding of this study is that shortening of the stimulus advertisement from eight to four pages had no damaging effect on any dependent measure. To be sure, two pages were eliminated by rearranging the visual syntax of the advertisement. However, we did remove outright two additional pages with peripheral pictures and still no adverse effects on advertisingperformance measures were obtained.

\section{IMPLICATIONS AND DIRECTIONS FOR FUTURE RESEARCH}

\section{Theoretical implications}

In keeping with Houston, Childers, and Heckler's (1987) exhortation to direct greater attention to studying the integration of visual and verbal cues in marketing communications, the primary goal of our study was to examine the role of pictures in advertisements by comparing the effectiveness of advertisements with more pictures with that of advertisements with fewer pictures. Moreover, our study was more comprehensive than previous research in several respects: (1) it examined the issue of more versus fewer pictures under varied conditions of clutter, processing effort, and exposure; (2) unlike many studies that have used either memory (Leong, Ang, and Tham, 1996) or attitude (Miniard et al., 1991) as dependent variables, our study examined both; (3) the stimulus advertisement was much longer (eight pages) than those used in previous studies; and (4) the stimulus advertisement was a real advertisement.

Our primary finding is that under the conditions used in our two studies, a fourpage version of a PPA is just as effective as 
its eight-page parent. Several other findings, though not related directly to the issue of more versus fewer pictures, are also important in that they extend our knowledge of how the effectiveness of pictorial advertisements varies under different conditions. For example, finding a disruptive effect of clutter on memory of and attitude toward the stimulus advertisement supports previous findings (e.g., Baumgardner, et al., 1983; Burke and Srull, 1988). Similarly, finding significantly higher pictorial recall in low-effort than in high-effort processing conditions supports Childers and Houston's (1984) hypothesis that conditions of low advertising-processing effort are more conducive to the learning of pictorial than to the learning of verbal material. That finding, seen within the framework of Batra and Ray's (1983) hierarchy of effects model (awareness $\rightarrow$ hedonic attitude $\rightarrow$ behavior $\rightarrow$ evaluative attitude) and coupled with the fact that low-effort processing leads to higher $A_{a d}$-affective, suggests that regardless of their length, the PPAs are better suited for low-involvement than for high-involvement products.

Finally, the finding that the affective and evaluative attitudinal responses to the two stimulus advertisements took opposite directions under the high- and the low-effort processing conditions underscores the importance of measuring both the affective and evaluative components of $\mathrm{A}_{\mathrm{ad}}$. Since its introduction in 1981 (Shimp, 1981; Mitchell and Olson, 1981), the $A_{a d}$ construct has been an important advertising response variable (see Mitchell, 1986). In his original work, Shimp conceptualized $\mathrm{A}_{\mathrm{ad}}$ as having two distinct dimensions, affective and evaluative. Yet, few studies addressing advertisements with pictures have examined the affective dimensions of $A_{a d}$. Given the mounting evidence that pictorial advertisements produce significant affective responses in low-involvement conditions, ignoring $A_{\text {ad }}$ 's affective dimension may be misleading. Clearly, ". . . by not acknowledging and attempting to operationalize such a distinction, researchers may be missing important information about individuals reactions to advertisements" (Madden, Allen, and Twible, 1988).

\section{Practical implications}

Our findings raise several managerial issues about the use of PPAs.

1. PPAs, with their many peripheral pictures, may be more suitable for lowinvolvement products than for highinvolvement products. High-involvement products, requiring effortful processing of the advertising claims, may not benefit from the inclusion of peripheral pictures.

2. Even where circumstances justify using a long PPA, the relative length of the advertisement must be considered. Many peripheral pictures in the long PPAs may be just that-peripheraland their inclusion ought to be justified in terms of advertising effectiveness. As Childers and Houston (1984) note, "The inclusion of pictorial material in print ads, for example, adds substantially to advertising production and media placement costs."

3. In recent years, media clutter has become such a major problem for advertisers that many advertising agencies have begun to negotiate media buys, at least for television programs, on the basis of clutter in the program (Mandese, 1991). In the print medium, one reason for the use of long PPAs is to cut through the competitive clutter. Here again, advertisers should carefully consider the number of peripheral pictures in their advertisements-especially if the advertisement is longer than two pages and, hence, above the noticeability criterion level.

4. Using multiple exposures of a short PPA may be a more efficient strategy for offsetting clutter than using a single exposure of a long PPA. For the conditions in our study, two exposures of a four-page PPA led to more than twice as many claims being recalled as did a single exposure of an eight-page PPA.

5. In some instances, using longer PPAs with irrelevant pictures may cause negative reaction and lower the attitude toward the advertisement, as was the case in the replication study.

If our results were to hold in a field setting, many advertisers could reduce the size of their PPAs significantly without loss of effectiveness, potentially achieving huge savings, as did General Motors, which according to Competitive Media Reporting figures spent $\$ 3.1$ billion on advertising in 1998.

The enormity of advertising spending in the United States raises the issue of possible misallocation of resources. Aaker and Carman (1982), on the basis of an exhaustive literature review, concluded that a substantial portion of advertising represents overspending under conditions of saturation and hence a misallocation of social resources. One way to lessen that problem may be for advertising agencies to do routine copytesting of short versions of long PPAs and to present the findings to clients. The impetus for using shorter PPAs may come from companies such as DaimlerChrysler, which recently reported a 0.2 percent decline in advertising spending (Advertising Age, March 22, 1999).

Our findings and the corresponding implications must be viewed in light of two limitations of our studies. First, though we enhanced the external validity of our findings by using a real advertisement for a product of interest to our subjects, the 
studies were conducted in a lab and should be replicated in more natural settings. Second, because we used an advertisement unfamiliar to subjects, the findings about attitude are limited to attitude formation and do not include attitude change.

Our findings raise a series of questions that should be answered in future research. For example, we shortened an eight-page PPA to four pages and did not alter effectiveness. What would happen if the advertisement were shortened even further? What if all peripheral pictures were removed? Would the shorter version be as effective, at least in the high-effort processing condition? What would happen if we started with a six-page advertisement and edited it down to three or even two pages? Research is needed to examine the effectiveness of a series of long PPAs with different initial lengths that are then shortened by various degrees. We could then ascertain the family of functional relationships, if any, between the effectiveness of initial length and that of shortened versions. AAB

SUREndra N. Singh is Southwestern Bell Chair in Marketing and Director, Research and Ph.D. programs at the University of Kansas. He received his Ph.D. from the University of Wisconsin, Madison in 1982. Dr. Singh's primary research interests are in marketing communications and services marketing.

V. Parker Lessig, Ph.D. is the Franks Pinet Distinguished Professor and Director of Undergraduate Programs at the University of Kansas School of Business. His primary research interests are in marketing strategy and market segmentation.

Dongwook KıM was an instructor at the University of Arkansas at the time of this research and is now with Michigan Technological University.

REETIKA Gupta was a doctoral student at the University of Kansas at the time of this research. She is now with Baruch College, City University of New York.

MARY ANN Hocutr is an assistant professor at Samford University, Birmingham, Alabama. She received her Ph.D. from Oklahoma State University. She has published articles in the Advances of Consumer Research, Journal of Quality Management, and International Journal of Service Industry Management. She has also presented many papers at AMA Educators' Conferences.

\section{REFERENCES}

AAKer, DAVID A., and JAMES M. CARMAN. "Are You Overadvertising?" Journal of Advertising Research 22, 4 (1982): 57-70.

ANDERSON, JoHn R., and LYNNE M. REDER. “An Elaborative Processing Explanation of Depth of Processing." In Levels of Processing in $\mathrm{Hu}$ man Memory, Laird S. Cermak and Fergus I. M. Craik, eds. Hillsdale, NJ: Lawrence Erlbaum Associates, 1979.

Batra, Rajeev. "Affective Advertising: Role, Processes, and Measurement." In The Role of Affect in Consumer Behavior, Robert A. Peterson, Wayne D. Hoyer, and William R. Wilson, eds. Lexington, MA: D. C. Heath and Company, 1986.

- and Michael L. Ray. "How Advertising Works at Contact." Working paper, Stanford University School of Business Administration, 1983.

Baumgardner, Michael H., Michael R. LEIPPE, DAVID L. RONIS, and ANTHONY G. GREENWALD. "In Search of Reliable Persuasion Effects: II: Associative Interference and Persistence of Persuasion in a Message-Dense Environment." Journal of Personality and Social Psychology 45 (1983): 524-37.

Biehal, Gabriel, and Dipankar Chakravarti. "Information Presentation Format and Learning Goals as Determinants of Consumers' Memory-Retrieval and Choice Processes." Journal of Consumer Research 8, 4 (1982): 43141.
BOLEN, William H. Advertising, second ed. New York: John Wiley \& Sons, Inc., 1984.

Burke, Raymond R., and Thomas K. SRull. "Competitive Interference and Consumer Memory for Advertising." Journal of Consumer Research 15, 1 (1988): 55-68.

Childers, Terry L., and Michael J. Houston. "Conditions for a Picture-Superiority Effect on Consumer Memory." Journal of Consumer Research 11, 2 (1984): 643-54.

COPLAND, Brian D. The Study of Attention Value: A Review of Some Available Material. London: Business Publications Limited, 1958.

CROWDER, R. G. Principles of Learning and Memory. Hillsdale, NJ: Lawrence Erlbaum Associates, 1976.

Edell, Julie A., and Richard Staelin. "The Information Processing of Pictures in Print Advertisements." Journal of Consumer Research 10, 1 (1983): 45-61.

FISK, ARTHUR D., and WALTER SCHNEIDER. "Memory as a Function of Attention, Level of Processing, and Automatization." Journal of Experimental Psychology: Learning, Memory and Cognition 10, 2 (1983): 181-97.

FRICK, ROBERT W. "Accepting the Null Hypothesis." Memory and Cognition 23, 1 (1995): 132-38.

Greenwald, Anthony G., and Clark Leavitt. "Audience Involvement in Advertising: Four Levels. Journal of Consumer Research 11, 1 (1984): 581-92.

Hanssens, Dominique M., and Barton A. WErrz. "The Effectiveness of Industrial Print Advertisements Across Product Categories." Journal of Marketing Research 17, 3 (1980): 294306.

Houston, Michael J., Terry L. ChIlders, and SuSAN E. HeCKLER. "Picture-Word Consistency and the Elaborative Processing of Advertisements. Journal of Marketing Research 24, 4 (1987): 359-69. 
KIRK, ROGER E. Experimental Design: Procedures for the Behavioral Sciences. Belmont, CA: Brooks/Cole, 1968.

Kistelius, Jolita, and Brian SternTHal. "Detecting and Explaining Vividness Effects in Attitudinal Judgments." Journal of Marketing Research 21, 1 (1984): 54-64.

LeOng, Siew Meng, Swee Hoon Ang, and Lai LENG THAM. "Increasing Brand Name Recall in Print Advertising Among Asian Consumers." Journal of Advertising 25, 2 (1996): 65-81.

Madden, Thomas J., Chris T. Allen, and JACQUELYN L. TWIBLE. "Attitude Toward the Ad: An Assessment of Diverse Measurement Indices Under Different Processing 'Sets'." Journal of Marketing Research 25, 3 (1988): 24252.

MANDESE, JOE. "Rival Spots Cluttering TV." Advertising Age, November 18, 1991.

MEYERs-LeVY, JOAN. “Elaborating on Elaboration: The Distinction Between Relational and Item-Specific Elaboration." Journal of Consumer Research 18, 3 (1991): 358-67.

Miniard, Paul W., Sunil Bhatla, KenNeth R. LORD, Peter R. Dickson, and H. Rao UnNava. "Picture-Based Persuasion Processes and the Moderating Role of Involvement." Journal of Consumer Research 18, 1 (1991): 92-107.

Mitchell, ANDREW A. "The Effect of Verbal and Visual Components of Advertisement on Brand Attitudes and Attitude Toward the Ad." Journal of Consumer Research 13, 1 (1986): $12-24$.

, and Jerry C. Olson. "Are Product Attribute Beliefs the Only Mediator of Advertising Effects on Brand Attitudes?" Journal of Marketing Research 18, 3 (1981): 318-32.

PaIvio, Allan. Mental Representation: A Dual Coding Approach. NY: Oxford Psychology Series No. 9, 1986.
PeChManN, Cornelia, and David W. Stewart.

"Advertising Repetition: A Critical Review on Wearin and Wearout." Current Issues and Research in Advertising 11, 2 (1988): 285-330.

PetTy, Richard E., and JoHN T. CACIOPPO. Attitudes and Persuasion: Classic and Contemporary Approaches. Dubuque, IA: Brown, 1981.

Rossiter, JOHN R. "Predicting Starch Scores." Journal of Advertising Research 31, 5 (1981): 63-68.

Russell, J. ThOMAs, and W. Ronald LANE. Kleppner's Advertising Procedure. Englewood Cliffs, NJ: Prentice-Hall, Inc., 1993.

ShIMP, Terence A. "Attitude Toward the Ad as a Mediator of Consumer Brand Choice." Journal of Advertising 10, 2 (1981): 9-15.

Silk, Alvin I., and Frank P. Geiger. "Advertisement Size and the Relationship Between Product Usage and Advertising Exposure." Journal of Marketing Research 9, 1 (1972): 22-26.

Singh, Surendra N., Michael L. Rothschild, and GIlbert A. Churchill, JR. "Recognition Versus Recall as Measures of Television Commercial Forgetting." Journal of Marketing Research 15, 1 (1988): 72-80.

UNNAVA, H. RAO, and ROBERT E. BURNKRANT. "An Imagery-Processing View of the Role of Pictures in Print Advertisements." Journal of Marketing Research 28, 2 (1991a): 226-31.

— and _ _ "Effects of Repeating Varied Ad Executions on Brand Name Memory." Journal of Marketing Research 28, 4 (1991b): 406-16.

- and DEEPAK SIRDESHMUKH. "Reducing Competitive Ad Interference." Journal of Marketing Research 31, 3 (1994): 403-11.

\section{APPENDIX}

\section{Description of various measures}

Manipulation Checks. Subjects responded to three questions designed as manipulation checks (Unnava and Burnkrant, 1991b). The first question was a seven-point (very much effort/very little effort) scale designed to indicate the amount of perceived effort spent on advertising processing. In the next two questions, subjects expressed their agreement on the following two five-point Likert summated ratings statements: (1) "I focused more on the appearance and layout of the advertisements than on any other feature in the ads" and (2) "I focused more on the information content in the ads than on any other feature in the ads." In comparison with their low-effort counterparts, the subjects in the high-effort processing condition were expected to expend greater effort in advertising processing and pay greater attention to the information content and less attention to appearance and layout.

Visual Imagery. Two measures were used to assess visual imagery. First, subjects rated the advertisements on a one-item, seven-point semantic differential scale with end anchors "vivid" and "dull." Next, they responded to four questions measuring the degree of visual imagery they experienced while they processed the stimulus advertisement (Unnava and Burnkrant, 1991a): "The ad brought pictures or images to my mind that helped clarify what was said in the advertisement," "As I read the ad, I formed pictures or images about much of what was being discussed in the ad," "I found myself thinking of images or pictures when I read the ad," and "It was easy to form images or pictures of what was being said in the ad" (coefficient alpha $=.91$ ). 
Uncued Brand Recall. The first memory test required subjects to list all brand names they could remember from the advertisements in the advertising folder.

Cued Brand Recall. Subjects were given the product category of the stimulus advertisement and asked to recall the brand name.

Claim Recall. Subjects were told the product category and the brand name depicted in the stimulus advertisement and were asked to recall everything they could remember from the advertisement.

\section{Attitudinal Measures}

Attitude Toward the Ad-Affective ( $\mathrm{A}_{\mathrm{ad}^{-}}$ affective). $A_{\text {ad }}$-affective, which measures "the low intensity and highly spontane- ous feeling states" on a 12-item semantic differential scale, was adopted from Madden, Allen, and Twible (1988). Subjects were asked to indicate how they felt while reading the stimulus advertisement. For each of 12 adjectives, they responded to the prompt "Did the (stimulus ad) make you feel..." on a scale ranging from 7 (very much so) to 1 (not at all). The 12 adjectives were: insulted, good, cheerful, irritated, impatient, pleased, repulsed, amused, confused, stimulated, shocked, and soothed (coefficient alpha $=.80$ ).

\section{Attitude Toward the Ad-Evaluative} ( $A_{a d}$-evaluative). The $A_{\text {ad }}$-evaluative scale, adopted from Madden, Allen, and Twible (1988), was an 11-item, sevenpoint semantic differential scale with the following adjectives: pleasant/unpleasant, likeable/unlikeable, interesting/ boring, tasteful/tasteless, entertaining/ boring, artful/artless, familiar/novel, good/bad, believable/unbelievable, convincing/unconvincing, and informative/ uninformative (coefficient alpha $=.91$ ).

Attitude Toward the Brand $\left(A_{B}\right)$. Attitude toward the brand was measured on a seven-item, seven-point semantic differential scale. The end descriptors were: like very much/dislike very much, useful/ useless, valuable/worthless, important/ unimportant, beneficial/not beneficial, fond of/not fond of, and enjoyable/ unenjoyable (coefficient alpha $=.94$ ).

Purchase Intentions (PI). The likelihood of purchasing the stimulus brand was assessed on a three-item, seven-point semantic differential scale with adjectives probable/improbable, likely/unlikely, and possible/impossible (coefficient alpha $=.95)$. 